\title{
Diagnóstico da COVID-19 em laboratórios de análises clínicas
}

\author{
Diagnosis of COVID-19 in clinical analysis laboratories \\ Diagnóstico de COVID-19 em laboratórios de análisis clínicos
}

Recebido: 01/01/2022 | Revisado: 06/01/2022 | Aceito: 11/01/2022| Publicado: 13/01/2022

\author{
Sônia Aparecida Figueiredo \\ ORCID: https://orcid.org/0000-0003-2549-4273 \\ Universidade Federal de Alfenas, Brasil \\ E-mail: soniaafigueiredo85@gmail.com \\ Fernanda Borges de Araújo Paula \\ ORCID: https://orcid.org/0000-0003-3077-3023 \\ Universidade Federal de Alfenas, Brasil \\ E-mail: fernandabap0@gmail.com
}

\begin{abstract}
Resumo
A partir de dezembro de 2019, uma nova pandemia assolou o mundo. O agente responsável pela nova doença é a síndrome respiratória aguda grave coronavírus 2 (SARS-CoV-2). Incessantemente, iniciou-se uma corrida contra o tempo para identificar e decodificar o genoma do coronavírus 2019 (COVID-19), com o intuito de aperfeiçoar seu diagnóstico. Por ser um problema de saúde, o laboratório de análises clínicas passou a ser peça chave no diagnóstico pois está presente na grande maioria das cidades brasileiras. Diante disso, o objetivo dessa revisão de literatura foi demonstrar quais tipos de testes de diagnósticos são passíveis de serem executados pelo laboratório de análises clínicas. A metodologia empregada foi a pesquisa bibliográfica a partir de fontes secundárias, onde empregou a base de dados ScienceDirect e Pubmed. O levantamento mostrou que o diagnóstico da COVID-19 pode ser baseado em: biomarcadores correlacionados ao próprio vírus (material genético), sendo que o teste padrão ouro é o ensaio da reação em cadeia da transcrição da polimerase reversa em tempo real (RT-PCR); em moléculas provenientes da resposta imunológica contra os antígenos virais (produção de anticorpos) por meio de testes sorológicos (imunoensaios enzimáticos, de micropartículas quimioluminescentes, de fluorescência e de fluxo lateral) e, em alterações na concentração de biomarcadores de órgãos afetados pelo vírus (marcadores inflamatórios, de funções renais e hepáticas, etc.). Assim, perante o crescente número de casos e o surgimento de novas variantes, é de extrema importância difundir conhecimentos e enfatizar a importância dos laboratórios clínicos no cotidiano das comunidades, frente a uma pandemia.
\end{abstract}

Palavras-chave: Diagnóstico; COVID-19; Laboratório de análises clínicas.

\begin{abstract}
From December 2019, a new pandemic ravages the world. The agent responsible for the new disease is the severe acute respiratory syndrome coronavirus 2 (SARS-CoV-2). Relentlessly, a race against time has begun to identify and decode the coronavirus 2019 (COVID-19) genome, in order to improve its diagnosis. Because it is a health problem, the clinical analysis laboratory has become a key player in the diagnosis because it is present in most Brazilian cities. Therefore, the aim of this literature review was to show which types of diagnostic tests can be performed by the clinical analysis laboratory. The methodology used was a bibliographic research from secondary sources, using the ScienceDirect and Pubmed database. The survey showed that the diagnosis of COVID-19 can be based on: biomarkers correlated to the virus itself (genetic material), the gold standard test being the real-time reverse transcription polymerase polymerase chain reaction (RT-PCR) assay; in molecules from the immune response against viral antigens (antibody production) by serological tests (enzyme immunoassays, chemiluminescent microparticle, fluorescence and lateral flow), and in changes in the concentration of biomarkers of organs affected by the virus (inflammatory markers, markers of kidney and liver function, etc.). Thus, in view of the increasing number of cases and the emergence of new variants, it is of utmost importance to spread knowledge and emphasize the importance of clinical laboratories in the daily life of communities, in the face of a pandemic.
\end{abstract}

Keywords: Diagnosis; COVID-19; Clinical analysis laboratory.

\section{Resumen}

A partir de diciembre de 2019, una nueva pandemia asola el mundo. El agente responsable de la nueva enfermedad es el coronavirus del síndrome respiratorio agudo severo 2 (SARS-CoV-2). Sin descanso, se ha iniciado una carrera contrarreloj para identificar y descifrar el genoma del coronavirus 2019 (COVID-19) con el fin de perfeccionar su diagnóstico. Por tratarse de un problema de salud, el laboratorio de análisis clínicos se convirtió en una pieza clave en el diagnóstico porque está presente en la mayoría de las ciudades brasileñas. Por lo tanto, el objetivo de esta revisión bibliográfica era demostrar qué tipos de pruebas diagnósticas puede realizar el laboratorio de análisis clínicos. La 
metodología utilizada fue una investigación bibliográfica a partir de fuentes secundarias, utilizando las bases de datos ScienceDirect y Pubmed. La encuesta mostró que el diagnóstico de COVID-19 puede basarse en: biomarcadores correlacionados con el propio virus (material genético), siendo la prueba de referencia el ensayo de reacción en cadena de la polimerasa con transcripción inversa (RT-PCR) en tiempo real; en las moléculas derivadas de la respuesta inmunitaria contra los antígenos virales (producción de anticuerpos) mediante pruebas serológicas (inmunoensayos enzimáticos, micropartícula quimioluminiscente, fluorescencia y flujo lateral) y, en los cambios en la concentración de biomarcadores de órganos afectados por el virus (marcadores inflamatorios, marcadores de la función renal y hepática, etc.). Así, ante el aumento del número de casos y la aparición de nuevas variantes, es de suma importancia difundir el conocimiento y destacar la importancia de los laboratorios clínicos en la vida cotidiana de las comunidades, ante una pandemia.

Palabras clave: Diagnóstico; COVID-19; Laboratorio de Análisis Clínicos.

\section{Introdução}

Desde o final do ano de 2019, a pandemia da doença coronavírus 2019 (COVID-19) tem atingido proporções globais. Essa enfermidade é causada pela nova síndrome respiratória aguda grave coronavírus 2 (SARS-CoV-2) (Goudouris, 2021; Ishige et al., 2020; Lai \& Lam, 2021; Sousa, G.O. et al., 2020). Sabe-se que existem seis tipos de coronavírus considerados infecciosos para a espécie humana, mas apenas dois subtipos $\beta$ desencadeiam sintomas graves (SARS-CoV e a Síndrome respiratória zoonótica do Oriente Médio - MERS-CoV) (Hellou et al., 2021; Sousa, M.R.N. et al., 2020).

Segundo a organização Mundial de Saúde (OMS), o fato do mundo não ter atingindo a meta de vacinação de $40 \%$ da população em 2021 permitiram o surgimento das variantes do SARS-CoV-2 (Nações Unidas, 2021). Com destaque para as Variantes de Preocupação (VOCs) que estão associadas com o aumento da transmissibilidade e virulência e diminuição da eficácia das vacinas, diagnósticos e terapêuticas (Lam et al., 2021).

Pesquisadores do mundo todo trabalham incessantemente na decodificação do genoma viral com o intuito de aperfeiçoar seu diagnóstico. Rapidamente foram surgindo protocolos de diagnóstico laboratorial padronizados (Carter et al., 2021; Lai \& Lam, 2021). Associados a esses métodos, diversos estudos têm reportado ensaios laboratoriais e exames complementares com boa sensibilidade e especificidade como preditores de diagnóstico para a COVID-19 (Goudouris, 2021 ; Vieceli et al., 2020).

Por ser um problema de saúde pública e de extrema relevância para a sociedade, o laboratório de análises clínicas passa a ser peça chave no diagnóstico da doença, seja no rastreamento de assintomáticos, no rastreamento populacional direcionado ao aumento de risco, no diagnóstico clínico, no monitoramento da gravidade da doença, dentre outras situações de prevenção e contenção da pandemia (Goudouris, 2021; Lai \& Lam, 2021).

Os centros de diagnóstico estão empregando como padrão ouro a reação em cadeia da transcrição da polimerase reversa em tempo real (RT-PCR) (durante a primeira semana de sintomas), testes sorológicos (a partir da segunda semana de sintomas), exames laboratoriais como hemograma completo, proteína C reativa (PCR), dímero-D, teste de coagulação, lactato desidrogenase (LD), ferritina e procalcitonina (para identificação de pior prognóstico) (Ishige et al., 2020; Goudouris, 2021). Esses testes devem ser precisos e robustos para garantir eficácia no controle da infecção (Karthik et al., 2020).

Sendo assim, o objetivo dessa revisão de literatura foi demonstrar quais tipos de análises são passíveis de serem executadas no laboratório de análises clínicas, ou seja, em laboratórios comerciais, para auxiliar no diagnóstico da COVID-19. Os resultados dos testes de diagnóstico têm aplicação direta para a sociedade e para o paciente internado e seus familiares, pois permitem que profissionais que atuam na linha de frente da pandemia possam retornar ao trabalho, possibilitam a definição do quadro clínico de pessoas suspeitas, propiciam a transferência ou não de pacientes para área de internação (unidades de terapia intensiva - UTI), medem o risco de contaminação de familiares e pessoas próximas, entre outras circunstâncias delicadas (Goudouris, 2021). 


\section{Metodologia}

O presente estudo corresponde a uma revisão narrativa que aborda os testes realizados em laboratórios de análises clínicas que auxiliam no diagnóstico da COVID-19. Ele foi elaborado de acordo com as normas descritas por Casarin et al. (2020); Ferenhof e Fernandes (2016) e Rother (2007).

Esta revisão baseou-se em um tema abrangente e de extrema relevância atual. As buscas foram fundamentadas em fontes primárias (relatórios técnicos, dissertações, teses, normas técnicas, artigos de periódicos) para realização da coleta de dados. Esta coleta ocorreu no período de janeiro a dezembro de 2021, sendo que para o levantamento de artigos científicos utilizou-se as bases de dados ScienceDirect e Pubmed e os descritores aplicados foram "Laboratory diagnosis of COVID-19" ou "Clinical test for COVID". A pesquisa embasou na seleção arbitrária de estudos mais relevantes que mencionavam testes diagnósticos executáveis em laboratórios de análises clínicas e excluiu trabalhos que citavam métodos com tecnologia de ponta e de custos exorbitantes, considerados inviáveis para esse tipo de laboratório. O fluxograma da Figura 1 exemplifica o processo de seleção dos artigos considerados mais expressivos pelas autoras, após aplicação dos filtros nas bases de dados. Vale ressaltar que ao aplicar o descritor "Clinical test for COVID" na base de dado Science Direct, os três artigos de interesse escolhidos pelas autoras, já tinham sido selecionados com o descritor "Laboratory diagnosis of COVID-19". Por esse motivo, não foram citados no fluxograma, mas foram mencionados na Tabela 1 . O mesmo fato ocorreu com a busca feita na base de dados PubMed. A Tabela 1 demonstra resumidamente os artigos escolhidos.

Figura 1: Fluxograma demonstrativo das pesquisas realizadas nas bases de dados (A) Science Direct e (B) Pubmed para seleção dos artigos considerados mais relevantes pelas autoras.

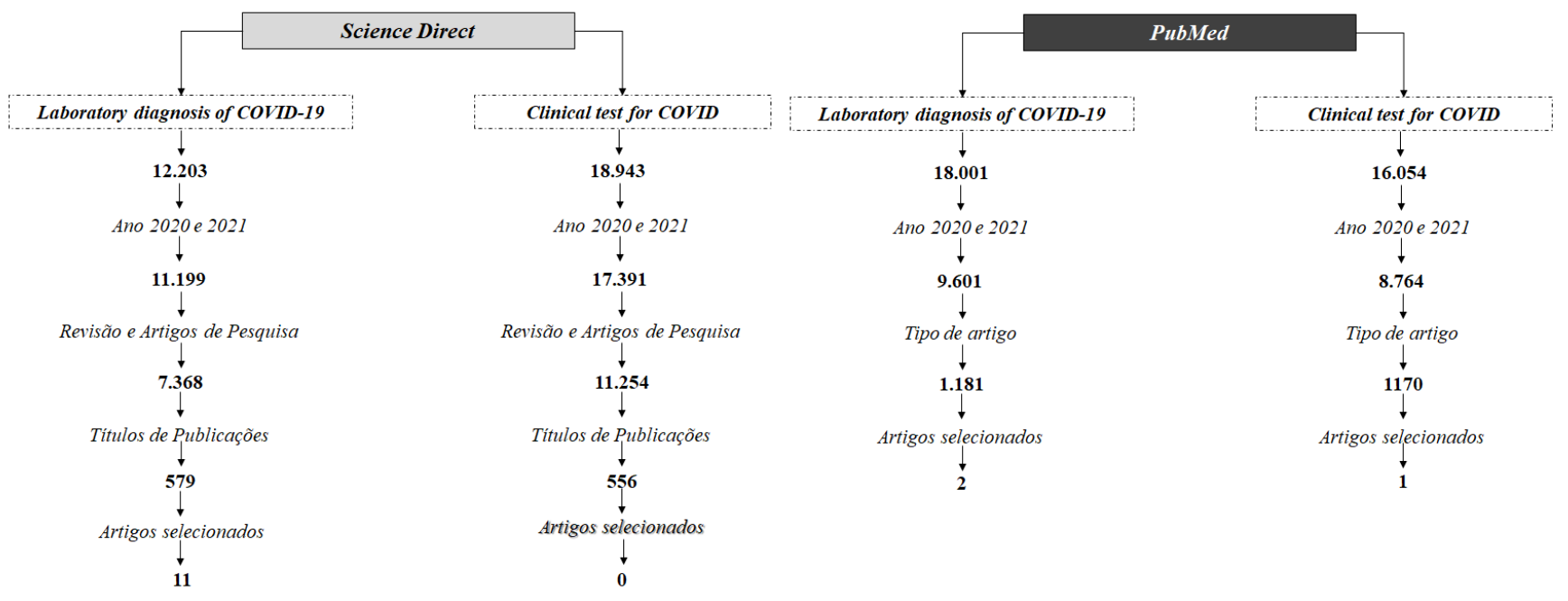

Fonte: Autores. 
Tabela 1: Lista de artigos científicos selecionados a partir das bases de dados Science Direct e PubMed.

\begin{tabular}{|c|c|}
\hline \multicolumn{2}{|c|}{ Science Direct - Laboratory diagnosis of COVID-19 } \\
\hline $\begin{array}{l}\text { Título do artigo } \\
\end{array}$ & Autores e Ano \\
\hline $\begin{array}{l}\text { Diagnosis and treatment of coronavirus disease } 2019 \\
\text { (COVID-19): Laboratory, PCR, and chest CT imaging } \\
\text { findings. }\end{array}$ & Abbasi-Oshaghi, E. et al., 2020. \\
\hline $\begin{array}{l}\text { Application of intelligence-based computational techniques } \\
\text { for classification and early differential diagnosis of COVID- } \\
19 \text { disease. }\end{array}$ & Akinnuwesi, B. A. et al., 2021. \\
\hline Laboratory diagnosis of COVID-19. & Goudouris, E. S., 2021. \\
\hline $\begin{array}{l}\text { Highly sensitive detection of SARS-CoV-2 by } \\
\text { multiplexrRT_PCR for molecular diagnosis of COViD-10 by } \\
\text { clinical laboratories. }\end{array}$ & Ishige, T. et al., 2020. \\
\hline $\begin{array}{l}\text { Laboratory diagnosis of COVID-19 in China: A review of } \\
\text { challenging cases and analaysis. }\end{array}$ & Jing, R. et al., 2021. \\
\hline Laboratory testing for the diagnosis of COVID-19. & Lai, C. K. C.; Lam, W., 2021. \\
\hline $\begin{array}{l}\text { Laboratory diagnosis of coronavirus disease-2019 (COVID- } \\
\text { 19). }\end{array}$ & Li, C. et al., 2020. \\
\hline Laboratory findings in COVID-19 diagnosis and prognosis. & Pourbagheri-Sigaroodi, A. et al., 2020. \\
\hline $\begin{array}{l}\text { Differential diagnosis and prospective grading of COVID-19 } \\
\text { at the early stage with simple hematological and biochemical } \\
\text { variables. }\end{array}$ & Song, L. et al., 2021. \\
\hline $\begin{array}{l}\text { Crucial laboratory parameters in COVID-19 diagnosis and } \\
\text { prognosis: An updated meta-analysis. }\end{array}$ & Soraya, G. V.; Ulhaq, Z. S., 2020. \\
\hline $\begin{array}{l}\text { A predictive score for COVID-19 diagnosis using clinical, } \\
\text { laboratory and chest image data. }\end{array}$ & Vieceli, T. et al., 2020. \\
\hline \multicolumn{2}{|c|}{ Science Direct-Clinical test for COVID } \\
\hline $\begin{array}{l}\text { Application of intelligence-based computational techniques } \\
\text { for classification and early differential diagnosis of COVID- } \\
19 \text { disease. }\end{array}$ & *Akinnuwesi, B. A. et al., 2021. \\
\hline Laboratory testing for the diagnosis of COVID-19. & *Lai, C. K. C.; Lam, W., 2021. \\
\hline $\begin{array}{l}\text { A predictive score for COVID-19 diagnosis using clinical, } \\
\text { laboratory and chest image data. }\end{array}$ & *Vieceli, T. et al., 2020 \\
\hline \multicolumn{2}{|c|}{ PubMed - Laboratory diagnosis of COVID-19 } \\
\hline $\begin{array}{l}\text { A review of epidemiology and public health control measures } \\
\text { of COVID-19 variants in Hong Kong, December } 2020 \text { to June } \\
2021 \text {. }\end{array}$ & *Lam, H. Y. et al., 2021. \\
\hline $\begin{array}{l}\text { Laboratory diagnosis of COVID-19: Current issues and } \\
\text { challenges. }\end{array}$ & Tang, Y.-W. et al., 2020. \\
\hline COVID-19 diagnosis - A review of current methods. & Yüce, M.; Filiztekin, E.; Özkaya, K. G., 2021. \\
\hline \multicolumn{2}{|c|}{ PubMed - Clinical test for COVID } \\
\hline Laboratory testing for the diagnosis of COVID-19. & *Lai, C. K. C.; Lam, W., 2021. \\
\hline $\begin{array}{l}\text { Laboratory diagnosis of coronavirus disease-2019 (COVID- } \\
\text { 19). }\end{array}$ & *Li, C. et al., 2020. \\
\hline $\begin{array}{l}\text { Diagnosis of COVID-19 for controlling the pandemic: A } \\
\text { review of the state-of-the-art. }\end{array}$ & Taleghani, N.; Taghipour, F., 2021. \\
\hline
\end{tabular}

* Artigos que foram selecionados em mais de uma base de dados. Fonte: Autores.

\section{Resultados e Discussão}

\subsection{A doença covid-19}

A humanidade vive uma nova pandemia, causada por um subtipo de betacoronavírus denominado de SARS-CoV-2. Esse vírus pertence à família Coronaviridae que é conhecida por causar doenças infecciosas tanto na espécie humana quanto animal. A COVID-19 tem transmissão respiratória e seus sintomas variam desde um leve resfriado ou estado gripal (tosse seca, febre, forte dor de cabeça e cansaço) até casos mais graves (danos à função de órgãos) podendo levar a morte (Goudouris, 2021; Pourbagheri-Sigaroodi et al., 2020; Sousa, G.O. et al., 2020; Taleghani; Taghipour, 2020). 
Os casos graves e de morte dessa doença atingiram todas as faixas etárias, com destaque, principalmente, para pacientes idosos ou aqueles que possuem sistema imunológico debilitado. Esse vírus tomou proporções pandêmicas muito rapidamente e o número de casos confirmados e de mortes aumentou drasticamente e diariamente. Após dois anos de pandemia (dezembro de 2021), esses números atingiram a marca de mais de 285 milhões de pessoas infectadas e mais de 5,42 milhões de mortes no mundo todo (Ritchie et al., 2021). E após uma melhora da crise com a expansão da vacinação, o mês de dezembro bateu o recorde mundial no número de novos casos em 24 horas e, por dois dias seguidos, houve o registro de mais de 1,3 milhão de casos (G1 Mundo, 2021). O Brasil é o terceiro país no ranking mundial em números de casos e o segundo no número de mortes, onde atingiu a triste marca de 618.723 mortes no dia 30 de dezembro de 2021 (Brüssow, 2021; Rosa et al., 2021; Ritchie et al., 2021).

A dificuldade em identificar os portadores assintomáticos e o surgimento das variantes do SARS-CoV-2 contribuem para a disseminação do vírus e, consequentemente, para o aumento do ciclo de contaminação. Os meses de março e abril de 2021 foram os mais letais da pandemia no Brasil, fato que levou ao colapso dos sistemas de saúde público e privado (R7Brasil, 2021; DW-Saúde, 2021). O Brasil conta com quatro vacinas aprovadas para uso: Coronavac, Janssen, AstraZeneca e Pfizer (Leme, 2021; Rosa et al., 2021) e a Sputnik com autorização para importação excepcional. A vacinação no Brasil atinge, em dezembro de 2021, a marca de $67,13 \%$ da população completamente imunizada e 75,55\% das pessoas receberam a primeira dose (G1-Coronavírus, 2021). No entanto, é necessário a aplicação de estratégias de rastreamento de pessoas em condição assintomática com a manutenção da testagem em massa e diagnóstico laboratorial rápido e precoce. Estes fatores, juntamente com o aumento do índice vacinal global, são imprescindíveis para controle e tratamento da doença, como também para evitar o aparecimento de novas variantes (Li et al., 2020; Taleghani; Taghipour, 2020; Akinnuwesi et al., 2021).

Merecem destaque também as medidas de saúde pública e sociais que são essenciais para o enfrentamento da doença: o uso obrigatório de máscaras faciais, distanciamento social, rastreamento de contato, controle de temperatura corporal e sintomas gripais, lavagem das mãos e o uso de álcool $70 \%$ e, minimização do convívio social e as aglomerações (Akinnuwesi et al., 2021).

\subsection{Diagnóstico}

A medicina laboratorial contribui efetivamente na vigilância epidemiológica, na definição do prognóstico da doença, no acompanhamento da evolução dos pacientes e também no monitoramento terapêutico de enfermidades como a COVID-19. Os achados laboratoriais anormais são parâmetros importantes para o diagnóstico e prognóstico do coronavírus (PourbagheriSigaroodi et al., 2020).

A coleta de amostras é uma etapa chave no diagnóstico laboratorial da COVID-19. Inicia-se com a adequada aquisição da amostra, advinda do local correto e no momento ideal da infecção (fase pré-analítica). Esses cuidados garantem um diagnóstico preciso e resultados confiáveis. Contudo, esse estágio das análises é a maior fonte de erros (46\% a 68\%) do processo. Na fase analítica, ocorre a seleção e execução dos testes disponíveis no laboratório para o diagnóstico, que também são passíveis de erros técnicos. E por último, há a interpretação e disponibilização dos dados em forma de laudo (fase pósanalítica) (Tang et al., 2020; Younes et al., 2020).

As amostras atualmente acessíveis para o diagnóstico da COVID-19 são: trato respiratório superior e inferior, amostras de fezes, amostras de sangue total e amostras de soro. Um destaque para os espécimes respiratórios que são os mais usados para o diagnóstico (Li et al., 2020).

O diagnóstico da COVID-19 pode ser baseado em biomarcadores correlacionados ao vírus responsável (material genético do microrganismo), em moléculas provenientes da resposta imunológica contra os antígenos virais (produção de 
anticorpos e testes sorológicos), em alterações na concentração de biomarcadores de órgãos afetados pelo vírus (marcadores inflamatórios, marcadores de funções renais e hepáticas, etc.) (Taleghani; Taghipour, 2020).

\subsubsection{Amostras clínicas para testes de covid-19}

Estudos da literatura relatam que o vírus SARS-CoV-2 foi identificado em amostras de esfregaços nasofaríngeos, orofaríngeos e de garganta, amostras de escarro, fluido de lavagem broncoalveolar, sangue total, soro, fezes, urina, saliva, esfregaços retais e conjuntivais ( $\mathrm{Li}$ et al., 2020).

A seleção do tipo de amostra a ser utilizada vai depender do cenário atual do contágio, das características clínicas do paciente e do estágio da doença (Lai \& Lam, 2021). Os espécimes do trato respiratório superior e inferior têm sido os principais alvos para o diagnóstico clínico da doença ativa (casos sintomáticos em estágios iniciais ou assintomáticos) (Lai \& Lam, 2021; Li et al., 2020).

Os tipos de amostras do trato respiratório superior que podem ser utilizadas são: esfregaços nasofaríngeo, orofaríngeo (garganta), nasais anteriores e de concha média, e aspirados nasofaríngeos ou uma combinação deles. Esses materiais são coletados com swabs nasofaríngeo ou orofaríngeo atóxicos, cuja técnica deve ser conduzida por profissional treinado e devidamente paramentado devido ao risco teórico de transmissão viral. Já a amostra do trato inferior de fácil coleta é a expectoração espontânea (Lai \& Lam, 2021; Tang et al., 2020).

Dados têm mostrado que a carga viral do trato respiratório inferior (expectoração, escarro) é maior que a do trato superior. Por isso, em caso de teste inicial negativo com espécimes do trato superior (amostra de primeira escolha), exames suplementares devem ser conduzidos com outros tipos de amostras (Lai \& Lam, 2021; Li et al., 2020).

Relatos revelam que a carga viral da saliva é maior logo após o início dos sintomas e reduz com o passar do tempo, sendo considerada uma amostra não invasiva promissora. Segundo a OMS, seu uso deve ser associado a outro tipo de amostra para diagnóstico (Lai \& Lam, 2021).

A detecção da COVID-19 no plasma é rara mas pode indicar o estágio grave a crítico da enfermidade. A coleta de soro, na fase aguda da doença (intervalo de 2-4 semanas), exibe um aumento de até quatro vezes nos títulos dos anticorpos (Lai \& Lam, 2021).

As amostras fecais são indicativas de doenças graves e no caso da COVID-19 podem ser consideradas em pacientes com fortes suspeitas clínicas, mas com resultados de trato respiratório negativo. Além de ser um tipo de amostra empregada na avaliação de cura e de infecciosidade com a realização de dois testes de RT-PCR consecutivos de esfregaços retais (Lai \& Lam, 2021; Tang et al., 2020; Yüce; Filiztekin, Özkaya, 2021).

\subsubsection{Testes moleculares}

Os testes moleculares são baseados no genoma viral (SARS-CoV-2), o qual é amplificado até atingir a concentração necessária para ser detectado pelos métodos existentes (Taleghani; Taghipour, 2020; Yüce; Filiztekin, Özkaya, 2021).

Até o momento, os genes alvo para detecção de SARS-CoV-2 englobam a codificação de proteínas estruturais como proteína do nucleocapsídeo $(\mathrm{N})$, proteína do envelope $(\mathrm{E})$, glicoproteína de superfície (S) e proteína de membrana (M); a codificação de gene da RNA polimerase dependente de RNA (RdRP) e de gene de poliproteínas ORF (Open Reading Frame) 1 (ORF1a e ORF1b) (LI et al., 2020; Yüce; Filiztekin, Özkaya, 2021).

O teste de rotina, padrão ouro, recomendado pela OMS e pela FDA (Food and Drug Administration) é o ensaio da RT-PCR, considerado valioso na fase inicial de infecção, até mesmo em pessoas assintomáticas (LI et al., 2020; Jing et al., 2020; Coltart, Collet-Fenson, 2021). Esta técnica é denominada por teste de amplificação do ácido nucleico (NAAT), que tem como alvo as sequências do material genético (específico do patógeno) que foram citados acima, sendo aplicada como teste de 
diagnóstico inicial preferido (Lai \& Lam, 2021; Taleghani; Taghipour, 2020). Este ensaio detecta regiões do genoma viral, foi desenvolvido em caráter emergencial e baseou-se em parâmetros analíticos laboratoriais (Ishige et al., 2020). As amostras empregadas neste teste correspondem a esfregaços orofaríngeos, escarro, aspirado nasofaríngeo, lavado broncoalveolar ou aspirado traqueal profundo (Abbasi-Oshaghi et al., 2020; Yüce; Filiztekin, Özkaya, 2021).

O teste RT-PCR promove a transcrição reversa, ou seja, converte o RNA viral em DNA complementar (cDNA) com amplificação de algumas regiões do cDNA. São necessários também primers específicos para amplificar determinada região do genoma e de sondas fluorescentes que emitem sinais após cada amplificação bem-sucedida. Com isso, é possível quantificar o material genético do vírus (Goudouris, 2021; Yüce; Filiztekin, Özkaya, 2021). Há no mercado kits com diferentes regiões do genoma. As execuções desses kits seguem protocolos que especificam a sequência de diferentes sondas e primers, como por exemplo o protocolo do Instituto Charité-Berlin. A sensibilidade e especificidade desses kits ficam em torno de $70 \%$ e $95 \%$, respectivamente, e alguns fatores podem alterar os resultados tais como fatores referentes ao vírus, fatores técnicos de obtenção e manuseio de amostra ou quantidade de carga viral da amostra (Goudouris, 2021; Coltart, Collet-Fenson, 2021).

No entanto, a técnica de RT-PCR é muito complexa e requer o uso de equipamentos caros, profissionais capacitados e treinados e condições ideais de biossegurança, o que o torna inviável para execução em laboratórios clínicos de pequeno porte (Li et al., 2020; Coltart, Collet-Fenson, 2021; Yüce; Filiztekin, Özkaya, 2021).

A implantação de tecnologias com resultados mais rápidos e de execução descentralizada pode minimizar a transmissão progressiva da doença. Com isso, o desenvolvimento por esse tipo de tecnologia pode proporcionar testes que sejam feitos próximos ao paciente e sem a necessidade de profissionais especializados (Coltart, Collet-Fenson, 2021). Como por exemplo, o desenvolvimento de kits de detecção que possibilitassem resultados mais rápidos (Taleghani; Taghipour, 2020).

Estes testes estão disponíveis comercialmente como a plataforma GeneXpert (Cepheid Company) que detecta o gene das proteínas estruturais E e $\mathrm{N}$ e o resultado é obtido em 45 minutos; o teste desenvolvido pela BGI Genomics Co. Ltd. que permite avaliar 192 amostras em cerca de 4 horas; a Bosch desenvolveu um teste automatizado em PCR multiplex com liberação de resultados em 2h30min, dentre tantos outros testes (Goudouris, 2021; Taleghani; Taghipour, 2020; Coltart, ColletFenson, 2021).

Há também os Point-of-care Tests que identificam proteínas de SARS-CoV-2, são indicados para regiões onde não há laboratórios especializados e são apropriados para uso em laboratórios clínicos. Eles proporcionam um aumento na quantidade de análises realizadas, a obtenção de resultados em um menor tempo e, consequentemente, na identificação de novos casos (Coltart, Collet-Fenson, 2021; Goudouris, 2021; Taleghani; Taghipour, 2020; Younes et al., 2020).

\subsubsection{Testes sorológicos}

Os testes sorológicos têm papel relevante pois contribuem na investigação de um surto em andamento, na análise retrospectiva da taxa de ataque ou na extensão do contágio e na avaliação contínua da imunidade para análise da proteção contra reinfecção. Além de serem considerados uma estratégia indireta de diagnóstico para infecções virais pois utilizam como instrumento de detecção a resposta do sistema imunológico. Essa estratégia tem como alvo os antígenos virais e os anticorpos (resposta humoral) produzidos pelo organismo contra a infecção viral prévia (Carter et al., 2021; Coltart, Collet-Fenson, 2021; Goudouris, 2021; Li et al., 2020; Taleghani; Taghipour, 2020).

A produção dos anticorpos específicos varia de acordo com a fase da doença. Anticorpos IgM começam a ser detectados a partir do quinto dia após início dos sintomas e correspondem a resposta imune inicial do corpo. Já os anticorpos IgA demonstram maior sensibilidade e começam a ser detectados precocemente (anterior ao IgM) em mucosas dos tratos respiratório e digestivo, saliva, lágrimas, sangue, trato geniturinário e nasofaringe. E por fim, a identificação dos anticorpos IgG inicia-se a partir do décimo dia depois do início dos sintomas e corresponde a resposta mais específica do sistema 
imunológico (quantificados na maioria dos testes sorológicos) (Figura 2). Em síntese, a quantificação de anticorpos não pode ser usada para diagnóstico precoce de COVID-19 (Goudouris, 2021; Taleghani; Taghipour, 2020; Jing et al., 2020).

Figura 2: Níveis de anticorpos produzidos a partir da curva de infecção da SARS-CoV-2.

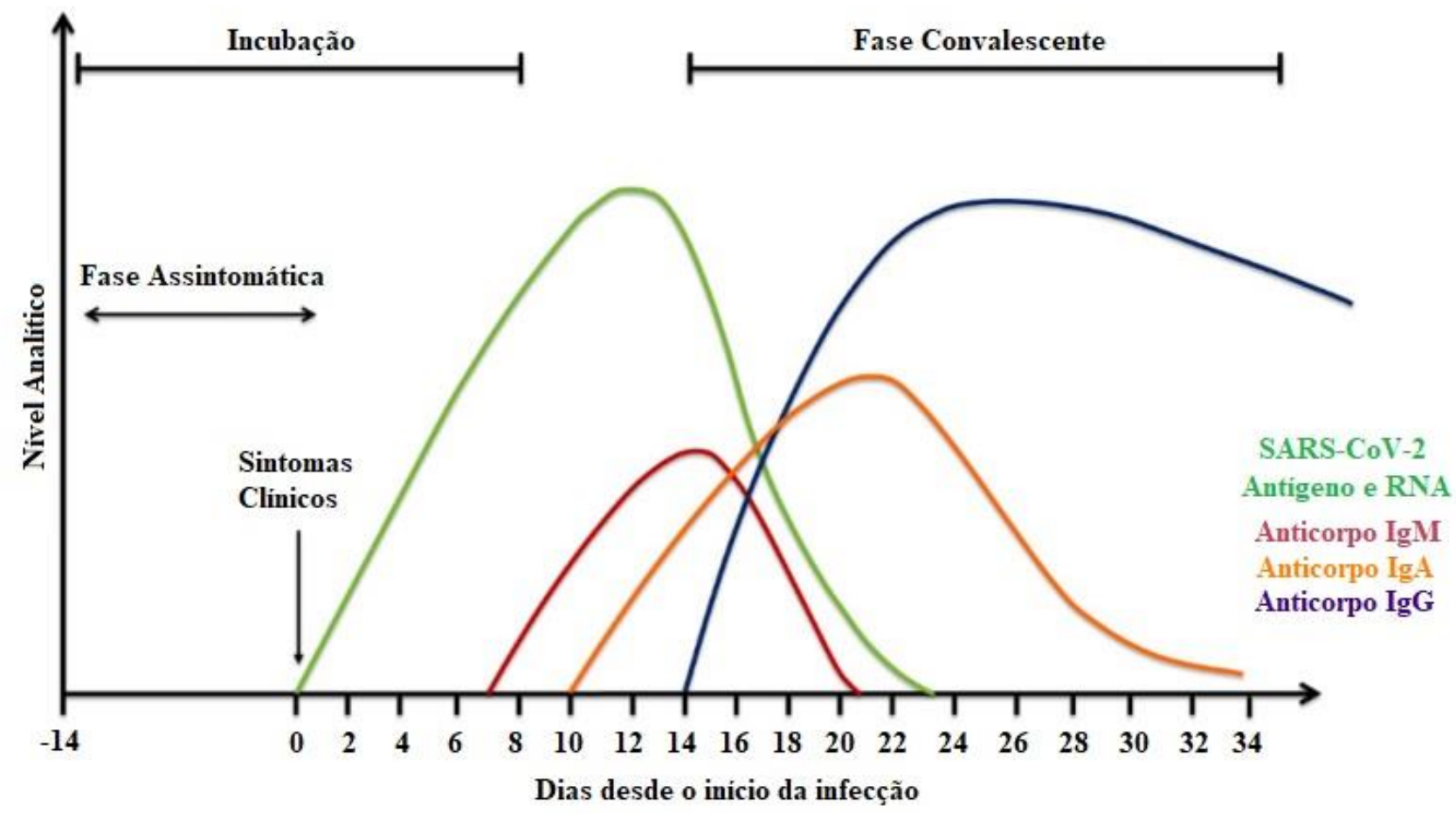

Fonte: Figura retirada de Younes et al. (2020) e traduzida para o português. IgM: Anticorpos Imunoglobulina M. IgA: Anticorpos Imunoglobulina A. IgG: Anticorpos Imunoglobulina G.

Há vários tipos de testes sorológicos que podem ser realizados por laboratórios comerciais tais como:

- Ensaios imunoenzimáticos (ELISA): desenvolvidos para identificação dos anticorpos $\operatorname{IgM}$ e $\operatorname{IgG}$ a partir de amostras de soro dos pacientes infectados (Goudouris, 2021; Taleghani; Taghipour, 2020; Younes et al., 2020; Zalzala, 2020).

- Imunoensaios de micropartículas quimioluminescentes: anticorpos específicos são imobilizados a micropartículas para que possam se ligar ao anticorpo alvo após adição da amostra. Após interação, os anticorpos marcados emitem fótons de luz (Goudouris, 2021; Taleghani; Taghipour, 2020).

- Ensaio de fluxo lateral: detecta antígenos virais e/ou anticorpos, assemelha-se a um teste de gravidez, mas a amostra utilizada é de sangue e não urina. É um teste de fácil execução, relativamente barato e de menor sensibilidade que o ensaio de RT-PCR. A amostra percorrerá a tira teste e se apenas a linha do controle estiver descolorida - teste negativo, se ambas as linhas (controle e teste) estiverem descoloridas - teste positivo. Este tipo de teste é apropriado para testes comunitários generalizados na detecção de casos infecciosos com alta disseminação viral (Goudouris, 2021; Taleghani; Taghipour, 2020; Zalzala, 2020; Coltart, Collet-fenson, 2021; Yüce; Filiztekin, Özkaya, 2021).

- Imunoensaio fluorescente para o antígeno SARS 2 (Sofia): utiliza a técnica de fluxo lateral baseada na imunofluorescência, onde a detecção engloba o design em sanduíche. O resultado está disponível em cerca de 15 minutos (Goudouris, 2021; Taleghani; Taghipour, 2020).

Segundo uma avaliação realizada pelo órgão de Saúde Pública da Inglaterra, os testes sorológicos têm uma sensibilidade elevada $(83,9 \%$ a $92,7 \%)$ e uma especificidade máxima (100\%) em condições laboratoriais. Entretanto, a 
precisão desses ensaios deve ser comparada com os resultados do teste padrão ouro (RT-PCR) o qual apresenta sua própria sensibilidade (Coltart, Collet-fenson, 2021).

Os ensaios sorológicos apresentam vantagens quando comparado com o teste rRT-PCR tais como deteç̧ão de infecções antecedentes, longa durabilidade dos anticorpos alvos de deteç̧ão (de semanas até meses), maior estabilidade das amostras sorológicas e fácil obtenção (Younes et al., 2020).

Uma inconveniência referente aos testes sorológicos, que merece atenção, é a reatividade cruzada. Esta reatividade ocorre quando um antígeno diferente do antígeno alvo se liga aos anticorpos. Isso pode acontecer por semelhanças estruturais das moléculas envolvidas na reação e a maior consequência desse processo é a obtenção de resultados falsos positivos para os testes. Um exemplo disso é um paciente infectado por SARS-CoV apresentar um resultado positivo para SARS-CoV-2 (Yüce; Filiztekin, Özkaya, 2021).

Devido a uma resposta imunológica tardia do organismo, o teste sorológico também pode se converter a um resultado falso negativo. Este fato pode significar que o paciente está infectado, mas ainda não produziu anticorpos em níveis detectáveis. Assim, a indicação dos testes sorológicos não é para diagnóstico precoce (Goudouris, 2021; Yüce; Filiztekin, Özkaya, 2021).

\subsubsection{Achados laboratoriais}

Na busca pelo diagnóstico da COVID-19 pode haver demora entre a realização do teste padrão ouro e a divulgação dos resultados. Para auxiliar nessa busca, outros parâmetros devem ser avaliados como o histórico do paciente, exames de imagem e parâmetros laboratoriais hematológicos e bioquímicos (Soraya; Ulhaq, 2020).

Achados laboratoriais como a leucocitose, trombocitopenia, eosinopenia, linfopenia e relação de neutrófilos/linfócitos $\geq 3,13$ estão relacionados a maior gravidade e a um mau prognóstico para COVID-19. Estudos mostram que leucócitos e neutrófilos estão significativamente aumentados em casos graves (Goudouris, 2021; Kavsak; Wit; Worster, 2020; PourbagheriSigaroodi et al., 2020; Song et al., 2021; Soraya; Ulhaq, 2020).

Os principais exames de rotina solicitados para o diagnóstico da COVID-19 englobam o hemograma completo para determinação quali e quantitativa das células sanguíneas, os testes de avaliação das cascatas de coagulação e fibrinólise (tempo de protrombina - TP, tempo de tromboplastina parcial ativada - TTPa e D-dímeros) e os parâmetros referentes à inflamação (taxa de sedimentação de eritrócitos - TSE, proteína C-reativa - PCR, ferritina e procalcitonina) (Goudouris, 2021; Pourbagheri-Sigaroodi et al., 2020).

A PCR é detectada na admissão da doença e na fase de hospitalização, corresponde a um marcador bastante sensível e disponível da inflamação. A linfopenia associada a trombocitopenia leve correspondem ao achado anormal mais comum entre em pacientes com COVID-19. TP e TTPa aumentados e associados a altos níveis de dímeros D também são relatados (coagulopatia). Parâmetros como a LD, creatina quinase (CK), ureia, creatinina, dentre outros, em altos níveis, sinalizam um pior prognóstico e fatores de risco para complicações e agravamento da doença. Já as análises bioquímicas auxiliam os médicos a avaliarem atividades funcionais de órgãos vitais gravemente acometidos pelo coronavírus (Goudouris, 2021; Kavsak; Wit; Worster, 2020; Pourbagheri-Sigaroodi et al., 2020).

Os achados bioquímicos anormais mais comuns em enfermos acometidos pela SARS-CoV-2 são: concentrações elevadas de LD, alanina aminotransferase (ALT), aspartato aminotransferase (AST), bilirrubina total (Bili), CK e creatinina e níveis reduzidos de albumina. Os níveis elevados da enzima LD (marcador de dano pulmonar), na maioria dos pacientes com COVID-19, está relacionado ao local primário de ação do vírus que corresponde ao trato respiratório inferior. Estágios graves da doença podem atingir outros órgãos como rins e fígado, identificados por quantificação de ALT e AST aumentados em 21,3\% e 22,2\% dos casos, respectivamente e, por níveis elevados de creatinina (Pourbagheri-Sigaroodi et al., 2020). 
Marcadores imunológicos como valores reduzidos de linfócitos T CD4+ e CD8+ e células Natural Killer (NK) e níveis elevados de citocinas como interleucina-6 (IL-6), IL-8, IL-10< INF- $\gamma$, TNF- $\alpha$, etc também representam fatores de maior gravidade e pior prognóstico para o coronavírus. Fatores inflamatórios como as citocinas são encontradas em altas concentrações na fase aguda (Goudouris, 2021; Pourbagheri-Sigaroodi et al., 2020).

\section{Conclusão}

O levantamento realizado mostrou que há diferentes testes que podem ser executados por laboratórios de análises clínicas e contribuir para o diagnóstico da COVID-19. Uma vez que, os laboratórios de análises clínicas estão presentes na grande maioria das cidades brasileiras, inclusive as de micro e pequeno porte. A escolha pelo método adequado depende da fase evolutiva da doença, do cenário atual do contágio, das características clínicas do paciente e do estágio da doença. Os métodos relatados na literatura possuem especificidade para cada fase da infecção e cada um deles dispõem de vantagens e desvantagens.

Entre os ensaios retratados neste estudo, os testes moleculares com RT-PCR foram mencionados por serem considerados o padrão ouro para o diagnóstico de coronavírus. No entanto, esta técnica não é indicada para execução em laboratórios clínicos de pequeno porte por requerer instalações e equipamentos específicos, profissionais treinados e qualificados, necessita de reagentes específicos, é mais dispendiosa e demorada que outras metodologias. Mas devido a demanda por testes de diagnósticos, kits de detecção que possibilitem resultados mais rápidos foram desenvolvidos e estão disponíveis no mercado.

Já os testes de sorologia destacam-se por possibilitar a identificação de pessoas que já foram contaminadas e as que estão atualmente doentes, permitindo obter um balanço real da infecção por COVID-19 na sociedade como um todo. O ponto negativo refere-se a não detecção do vírus em si, mas sim do anticorpo produzido pelo organismo contra ele. Este fato pode gerar resultados falso-negativos na fase inicial de contágio.

E por último, os achados laboratoriais têm grande contribuição no diagnóstico de COVID-19 pois permitem discriminar pacientes em estágios graves de leves. Uma vez que, apresentam níveis visivelmente mais elevados de parâmetros como os bioquímicos e os hematológicos. Essas alterações ocorrem em decorrência da infecção viral afetar diferentes órgãos.

Vale ressaltar que é importante combinar os métodos de diagnóstico discutidos nessa revisão com técnicas radiográficas e de tomografia computadoriza do tórax em casos de resultados falso-negativos para obter melhor exatidão e precisão no diagnóstico.

Pesquisas mais recentes mencionam como a mais nova estratégica para auxílio no diagnóstico de COVID-19: métodos de inteligência computacional. Este modelo aplica algoritmos com a finalidade de identificar os sintomas dos pacientes, desempenhos, as métricas usadas para medir os desempenhos e suas limitações. Estudos futuros nessa vertente contribuirão para diagnósticos e classificações quase $100 \%$ precisos.

\section{Referências}

Abbasi-Oshaghi, E.; Mmirzaei, F.; Farahani, F.; Khodadadi, I.; Tayebinia, H. (2020). Diagnosis and treatment of coronavirus disease 2019 (COVID-19): Laboratory, PCR, and chest CT imaging findings. International Journal of Surgery, 79, 143-153. https://doi.org/10.1016/j.ijsu.2020.05.018

Akinnuwesi, B. A. et al. (2021). Application of intelligence-based computational techniques for classification and early differential diagnosis of COVID-19 disease. Data Science and Management, In press. https://doi.org/10.1016/j.dsm.2021.12.001

Brüssow, H. (2021). COVID-19 by numbers - infections, cases and deaths. Environmental Microbiology, 23(3), 1322-1333. https://doi.org/10.1111/14622920.15377

Carter, C. et al. (2021). SARS-CoV-2 diagnostics: Towards a more comprehensive approach to routine patient testing. Journal of Immunological Methods, 494, 113044. https://doi.org/10.1016/j.jim.2021.113044 
Casarin, S. T. et al. (2020). Tipos de revisão de literatura: considerações das editoras do Journal of Nursing and Health. Journal of Nursing and Health, 10: e20104031. https://periodicos.ufpel.edu.br/ojs2/index.php/enfermagem/article/view/19924

Coltart, C. E. M.; Collet-Fenson, L. (2021). Future development in the prevention, diagnosis and treatment of COVID-19. Best Practice \& Research Clinical Obstetrics and Gynaecology, In press. https://doi.org/10.1016/j.bpobgyn.2021.03.012

DW-Brasil. (2021). “O sistema de saúde já colapsou, e vai continuar no colapso”. https://amp.dw.com/pt-br/o-sistema-de-sa\%C3\%BAde-j\%C3\%A1colapsou-e-vai-continuar-no-colapso/a-57130268

Ferenhof, H. A.; Fernandes, R. F. (2016). Desmisticando a revisão de literatura como base para redação científica: Método SSF. Revista ACB: Biblioteconomia, 21(3): 550-563.

G1-Coronavírus. (2021). Vacinação contra Covid: mais $d \quad 143$ milhões estão totalmente imunizados. https://g1.globo.com/saude/coronavirus/vacinas/noticias2021/12/29/vacinação-contra-a-covid-mais-de-143-milhoes-estao-totalmente-imunizados-13-estadose-o-df-nao-divulgaram-dados-de-vacinas.ghtml

G1-Mundo. (2021). Pelo segundo dia consecutivo, mundo ultrapassa marca de 1 milhão de casos de Covid em 24 horas http://g1.globo.com/mundo/noticia/2021/12/29/pelo-segundo-dia-consecutivo-mundo-ultrapassa-marca-de-1-milhao-de-casos-de-covid-em-24-horas.ghtml

Goudouris, E. S. (2021). Laboratory diagnosis of COVID-19. Jornal de Pediatria, 97(1), 7-12. https://doi.org/10.1016/j.jped.2020.08.001

Hellou, M. M. et al. (2021). Nucleic acid amplification tests on respiratory samples for the diagnosis of coronavirus infections: a systematic review and metaanalysis. Clinical Microbiology and Infection, 23(3), 341-351. https://doi.org/ 10.1016/j.cmi.2020.11.002

Ishige, T. et al. (2020). Highly sensitive detection of SARS-CoV-2 by multiplexrRT_PCR for molecular diagnosis of COViD-10 by clinical laboratories. Clinica Chimica Acta, 507, 139-142. https://doi.org/ 10.1016/j.cca.2020.04.023

Jing, R. et al. (2021). Laboratory diagnosis of COVID-19 in China: A review of challenging cases and analaysis. Journal of Microbiology, Immunology and Infection, 54(1), 17-26. https://doi.org/10.1016/j.jmii.2020.10.004

Karthik, K. et al. (2020). Biosafety concerns during the collection, transportation, and processing of COVID-19 samples for diagnosis. Archives of Medical Research, 51, 623-630. https://doi.org/10.1016/j.arcmed.2020.08.007

Kavsak, P. A.; Wit, K.; Worster, A. (2020). Emerging key laboratory tests for patients with COVID-19. Clinical Biochemistry, 81, 13-14. https://doi.org/10.1016/j.clinbiochem.2020.04.009

Lai, C. K. C.; Lam, W. (2021). Laboratory testing for the diagnosis of COVID-19. Biochemical and Biophysical Research Communications, 538, 226-230. https://doi.org/10.1016/j.bbrc.2020.10.069

Lam, H. Y. et al. A review of epidemiology and public health control measures of COVID-19 variants in Hong Kong, December 2020 to June 2021. IJID Regions, 2, 16-24. https://doi.org/10.1016/j.ijregi.2021.11.002

Leme, L. (2021). Veja quais são as vacinas contra covid-19 já aprovadas para aplicação no Brasil. https://www.acidadeon.com/campinas/cotidiano/vacinas/NOT,0,0,1600052,confira-as-vacinas-contra-covid-19-ja-aprovadas-para-aplicacao-no-brasil.aspx

Li, C. et al. (2020). Laboratory diagnosis of coronavirus disease-2019 (COVID-19). Clinica Chimica Acta, 510, 35-46. https://doi.org/10.1016/j.cca.2020.06.045

Nações Unidas. (2021). Para OMS, falha na meta de vacinar 40\% da população é “vergonha moral”. https://news.un.org/pt/story/2021/12/1775062

Pourbagheri-Sigaroodi, A.; Bashash, D.; Fateh, F.; Abolghasemi, H. (2020). Laboratory findings in COVID-19 diagnosis and prognosis. Clinica Chimica Acta, 510, 475-482. https://doi.org/10.1016/j.cca.2020.08.019

Rosa, A.; Lorenzetti, E.; Alecrim, G.; Cocolo, V. (2021). Brasil ultrapassa $400 \quad$ mil mortes por Covid-19. https://www.cnnbrasil.com.br/saude/2021/04/29/brasil-ultrapassa-400-mil-mortes-por-covid-19

Rosa, M. F. F. et al. (2021). Direct from the COVID-19 crisis: research and innovation sparks in Brazil. Health Research Policy and Systems, 19(10), 1-7. https://doi.org/10.1186/s12961-020-00674-x

Rother, E. T. (2007). Revisão sistemática X revisão narrativa. Acta Paulista de Enfermagem, 20(2): v-vi. https://doi.org/10.1590/S0103-21002007000200001

Ritchie, H. et al. (2021). Coronavirua Pandemic (COVID-19). Published online at OurWorldInData.org. Disponível em: $<$ https://ourworldindata.org/coronavirus>.

R7-Brasil. (2021). Mortes por Covid caem em relação a abril, mas maio é o $3^{\circ}$ pior mês. https://noticias.r7.com/brasil/mortes-por-covid-caem-em-relacao-aabril-mas-maio-e-o-3-pior-mes-09062021

Song, L. et al. (2021). Differential diagnosis and prospective grading of COVID-19 at the early stage with simple hematological and biochemical variables. Diagnostic Microbiology and Infections Disease, 99 (2), 115169. https://doi.org/10.1016/j.diagmicrobio.2020.115169

Soraya, G. V.; Ulhaq, Z. S. (2020). Crucial laboratory parameters in COVID-19 diagnosis and prognosis: An updated meta-analysis. Medicina Clinica, 155(4), 143-151. https://doi.org/10.1016/j.medcle.2020.05.004

Sousa, G. O. et al. (2020). Evolução epidemiológica da COVID-19 no Brasil e no mundo. Research, Society and Development, 9(7), e630974653. https://doi.org/10.33448/rsd-v9i7.4653 
Research, Society and Development, v. 11, n. 1, e49511125286, 2022

(CC BY 4.0) | ISSN 2525-3409 | DOI: http://dx.doi.org/10.33448/rsd-v11i1.25286

Sousa, M. R. N. et al. (2020). Patogênese e perspectivas de tratamento da Covid-19: uma revisão. Research, Society and Development, 9(7), e05973730. https://doi.org/10.33448/rsd-v9i7.3730

Taleghani, N.; Taghipour, F. (2021). Diagnosis of COVID-19 for controlling the pandemic: A review of the state-of-the-art. Biosensors and Bioelectronics, 174, 112830. https://doi.org/10.1016/j.bios.2020.112830

Tang, Y.-W.; Schmitz, J. E.; Persing, D. H.; Stratton, C. W. (2020). Laboratory diagnosis of COVID-19: Current issues and challenges. Journal of Clinical Microbiology, 58(6), e00512-20. https://doi.org/10.1128/JCM.00512-20

Vieceli, T. et al. (2020). A predictive score for COVID-19 diagnosis using clinical, laboratory and chest image data. The Brazilian Journal of Infectious Diseases, 24(4), 343-348. https://doi.org/ 10.1016/j.bjid.2020.06.009

Younes, N. et al. (2020). Challenges in laboratory diagnosis of the novel Coronavirus SARS-CoV-2. Viruses, 12(6), 582. https://doi.org/10.3390/v12060582

Yüce, M.; Filiztekin, E.; Özkaya, K. G. (2021). COVID-19 diagnosis - A review of current methods. Biosensors and Bioelectronics, 172, 112752. https://doi.org/10.1016/j.bios.2020.112752

Zalzala, H. H. (2020). Diagnosis of COVID-19: facts and challenges. New Microbes and New Onfections, 38, 100761. https://doi.org/ 10.1016/j.nmni.2020.100761 